\title{
Reversible Bicarbonate-Induced Enzyme Activity and the Point of no Return during Morphogenesis in Blastocladiella
}

\author{
By J. S. LOVETT* and E. C. CANTINO \\ Department of Botany and Plant Pathology, Michigan State University, \\ East Lansing, Michigan, U.S.A.
}

(Received 18 July 1960)

\begin{abstract}
SUMMARY
With synchronous single-generation cultures of the non-filamentous water fungus Blastocladiella emersonii the activities of isocitric dehydrogenase, $\alpha$-ketoglutaric dehydrogenase, and cytochrome oxidase were studied during morphogenesis. The total isocitric dehydrogenase activity per plant increased rapidly following germination of the spore and reached its peak at the point of no return in ontogeny; this increase was about seven times greater than the increase in total $\alpha$-ketoglutaric dehydrogenase activity. During growth from the spore stage to the stage of irreversibility, the specific activity of isocitric dehydrogenase increased $350 \%$ while that of $\alpha$-ketoglutaric dehydrogenase decreased $50 \%$. By removing the external bicarbonate before the point of no return was reached, and thus reversing the morphogenetic pathway, the specific activity of isocitric dehydrogenase, which was in the process of increasing, decreased immediately, while the $\alpha$-ketoglutaric dehydrogenase activity, which had decreased sharply, increased quickly once again. Similarly, the total activity of isocitric dehydrogenase per plant decreased precipitously while, without reversal, it continued to rise. Conversely, reversal of the morphogenetic path caused an immediate rise in the total $\alpha$-ketoglutaric dehydrogenase activity per plant while, in the absence of reversal, enzyme activity remained on a level plateau. Thus, removal of bicarbonate induced a new morphogenetic path and, simultaneously, a $250 \%$ increase in the activity of one key enzyme and a $35 \%$ decrease in the activity of a second; on the other hand, the total protein and total activity of two other 'control' enzymes (glucose-6-phosphate dehydrogenase and cytochrome oxidase) remained essentially constant. In contrast to the above, removal of bicarbonate immediately after the point of no return in morphogenesis had no significant effect on these same enzymes. The data provide substantial evidence that a reversible bicarbonate-induced enzyme synthesis is involved in morphogenesis; i.e. in the mechanism of the bicarbonate-induced formation of resistant-sporangial plants in Blastocladiella.
\end{abstract}

\section{INTRODUCTION}

Of the two major morphogenetic pathways that can be taken by a spore of Blastocladiella emersonii, the one which leads to a two-celled thick-walled brown-

* Present address: Department of Biological Sciences, Purdue University, West Lafayette, Indiana, U.S.A. 
pitted resistant sporangial (RS) plant is induced by bicarbonate. In the absence of bicarbonate, a thin-walled papillate ordinary-colourless (OC) plant is formed. Up to a certain point of no return in ontogeny, the young developing $R S$ plant can be made to revert to an $\mathrm{OC}$ plant by removing the bicarbonate from its immediate environment. Similarly, before a critical stage in ontogeny, a young OC plant can be induced to form an RS plant by providing it with bicarbonate. But beyond this point of no return, these two diverse morphological pathways become fixed and irreversible. Previous studies have led to the belief that bicarbonate exerts its effect by interfering with decarboxylation sites in the tricarboxylic acid cycle and that, while some enzyme activities of the cycle are consequently lost, a triphosphopyridine nucleotide (TPN)-specific isocitric dehydrogenase remains active and mediates $\mathrm{CO}_{2}$ fixation via reductive carboxylation of $\alpha$-ketoglutarate. This bicarbonate trigger mechanism has been discussed in recent reviews (Cantino \& Turian, 1959; Cantino, 1960, 1961).

The purpose of the work to be described here was threefold. (i) To look for precise and direct evidence, by using single-generation synchronous-culture techniques that (a) the $\alpha$-ketoglutaric dehydrogenase system (which was expected to interfere with the bicarbonate trigger mechanism in that it would tend to compete with isocitric dehydrogenase by removing $\alpha$-ketoglutarate from the carboxylating site) was either lost or severely diminished before the point of no return was reached during the bicarbonate-induced development of an RS plant, while $(b)$ the isocitric dehydrogenase (essential for the reductive carboxylation of $\alpha$-ketoglutarate) either increased in activity or, at least, remained fully functional. (ii) To look for direct evidence that reversal of the morphogenetic pathway (by removal of bicarbonate before the point of no return) caused a corresponding reversal in the activity of these enzymes, believed to be directly implicated in the bicarbonate trigger mechanism, but not in other enzymes more distantly removed from the locus of the bicarbonate effect. (iii) To look for direct evidence that, conversely, removal of bicarbonate after the point of no return in development did not induce significant changes in these same enzymic activities.

\section{METHODS}

Procedures for maintenance of stock cultures, and for the growth, sampling and harvesting of large-scale synchronous cultures of Blastocladiella emersonii were described previously (Lovett \& Cantino, 1960a, b). Cultures were grown with aeration in a water bath at $\mathbf{2 4 ^ { \circ } \pm \mathbf { 0 . 0 2 }}{ }^{\circ}$. Zoospores were harvested and washed for enzyme studies according to McCurdy \& Cantino (1960).

With the exception of zoospores, plants were homogenized in a Serval Omnimixer using $1.0 \mathrm{~g}$. wet weight $/ 10 \mathrm{ml}$. phosphate buffer $(0.05 \mathrm{M} ; \mathrm{pH} 6.8)$ and $10 \mathrm{~g}$. washed glass beads (200 $\mu$ diam., Minnesota Mining and Manufacturing Co.). For zoospores we used $\mathbf{0 . 2} \mathrm{ml}$. packed organism (equiv. $25.0 \mathrm{mg}$. dry wt.) $/ 10 \mathrm{ml}$. buffer $+10 \mathrm{~g}$. beads. Dry weights were obtained for all samples in order to calculate the per plant data (Lovett \& Cantino, 1960 b). Homogenates were centrifuged for $5 \mathrm{~min}$. at 14,500 $\mathrm{g}$ and the supernatant fluids used as the enzyme source. The entire procedure was carried out between 0 and $5^{\circ}$. Soluble protein in these preparations was determined by the turbidimetric method of Stadtman Novelli \& Lipmann (1951), with slight modification. 
In earlier studies (Cantino \& Hyatt, 1953), the diphosphopyrimidine nucleotide (DPN)-dependent $\alpha$-ketoglutaric dehydrogenase in Blastocladiella was assayed spectrophotometrically by following the reduction of nucleotide at $340 \mathrm{~m} \mu$ or reduction of cytochrome $c$ (via carrier nucleotide) at $550 \mathrm{~m} \mu$ with a cyanide block for the terminal oxidase. In the present experiments, we followed the disappearance of $\alpha$-ketoglutarate directly by chromatographic isolation and analysis of its 2, 4dinitrophenylhydrazone (modified from Cavallini \& Frontali, 1953; Cavallini \& Mondovi, 1957). The specific activity of $\alpha$-ketoglutaric dehydrogenase was defined as follows: $\mu$ mole $\alpha$-ketoglutarate disappearing $/ 30 \mathrm{~min} . / \mathrm{mg}$. protein in a standard assay containing $c$. 2-8 mg. protein, $100 \mu$ mole phosphate buffer $(\mathrm{pH} \mathrm{6} \cdot 8), 0 \cdot 15 \mu \mathrm{mole}$ coenzyme A, 0.25 $\mu$ mole DPN, $50 \mu$ mole potassium $\alpha$-ketoglutarate, in a final volume of $3.0 \mathrm{ml}$., at $30^{\circ}$. The reaction was stopped by acidification in a boiling water bath.

The activities of isocitric dehydrogenase, cytochrome oxidase, and the glucose6-phosphate/16-phosphogluconic dehydrogenases (the latter two being equally active in OC plants (Cantino \& Horenstein, 1959), and here assayed together as a unit, for simplicity and referred to as glucose-6-phosphate dehydrogenase) were determined spectrophotometrically under standardized assay conditions. In each case the specific activity has been expressed as units/mg. protein. For isocitric dehydrogenase and cytochrome oxidase, one unit was defined as an optical density change of $0.001 / \mathrm{min}$. in the standard assay. For glucose-6-phosphate dehydrogenase, one unit was defined as an optical density change of $0.1 / \mathrm{min}$. in the standard assay. All rates were determined as the average optical density change/min. (corrected for endogenous controls) for the first $3 \mathrm{~min}$. following the addition of enzyme.

The assay for isocitric dehydrogenase contained $c .0 \cdot 45 \mathrm{mg}$. protein, $100 \mu$ mole phosphate buffer (pH 6.8), $0.5 \mu$ mole TPN, 0.3 $\mu$ mole $\mathrm{KCN}, 10 \mu$ mole $\mathrm{MgCl}_{2}$, with and without $20 \mu$ mole sodium isocitrate, in a final volume of $3.0 \mathrm{ml}$., and the optical density change followed at $340 \mathrm{~m} \mu$. The assay for cytochrome oxidase contained c. $0.7 \mathrm{mg}$. protein, $100 \mu$ mole phosphate buffer (pH 6.8), $0.068 \mu$ mole cytochrome $c$ (reduced with $\mathrm{Na}_{2} \mathrm{~S}_{2} \mathrm{O}_{3}$ followed by aeration to remove $\mathrm{SO}_{2}$ ), with and without $0.3 \mu$ mole $\mathrm{KCN}$, in a final volume of $3.0 \mathrm{ml}$., and the optical density change followed at $550 \mathrm{~m} \mu$. The glucose-6-phosphate dehydrogenase assay contained c. $0.06 \mathrm{mg}$. protein, $50 \mu$ mole phosphate buffer (pH 7.0), $10 \mu$ mole $\mathrm{MgCl}_{2}, 0.5 \mu$ mole TPN, with and without $30 \mu$ mole glucose-6-phosphate, in a final volume of $3.0 \mathrm{ml}$., and the optical density change followed at $340 \mathrm{~m} \mu$.

The values per plant were calculated from the known dry weights used in the experiments and the dry weight of individual plants at various stages in ontogeny as previously described (Lovett \& Cantino, $1960 \mathrm{~b}$ ).

\section{RESULTS}

The activity of isocitric dehydrogenase, $\alpha$-ketoglutaric dehydrogenase, and cytochrome oxidase during the growth of an RS plant

The total activity per plant of the isocitric dehydrogenase increased quickly during the growth of an RS plant up to its point of no return and reached a value almost 7000 times that of the spore, while net synthesis of the $\alpha$-ketoglutaric dehydrogenase activity increased much less rapidly and reached a final value which was only about one-tenth of this amount (Fig. 1). During this same developmental 
period, the specific activity of the isocitric dehydrogenase increased $c .350 \%$ while, on the other hand, the specific activity of $\alpha$-ketoglutaric dehydrogenase increased slightly and then actually decreased to about $50 \%$ of its original value in the spore (Fig. 2). The activity (not plotted) of the terminal cytochrome oxidase of Blastocladiella emersonii followed a course essentially identical with that of $\alpha$-ketoglutaric dehydrogenase. The final activity of both $\alpha$-ketoglutaric dehydrogenase and cytochrome oxidase in fully mature RS plants is essentially zero (Cantino $\&$ Horenstein, 1955).

\section{Changes in the reversibility of enzymic activity before and after the point of no return during morphogenesis}

Plants of Blastocladiella emersonii were grown up to a stage ( $32 \mathrm{hr}$. at $\left.24^{\circ}\right)$ just preceding the point of no return, removed from the medium, freed from bicarbonate

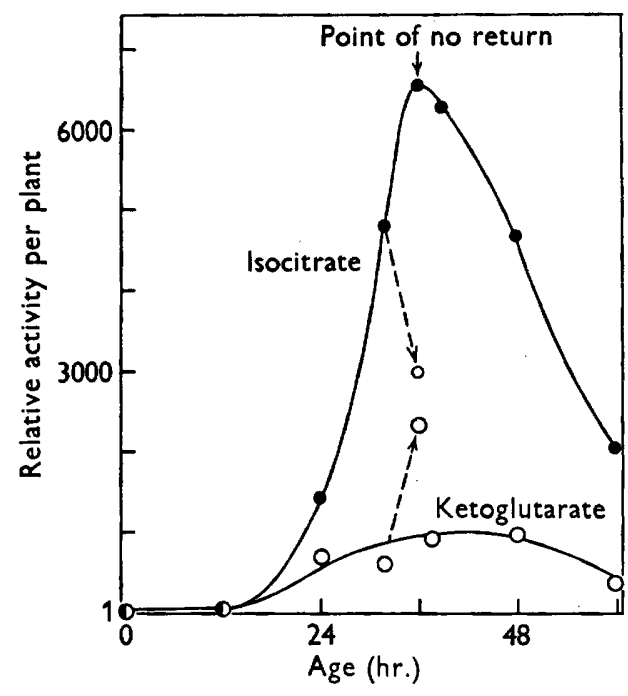

Fig. 1

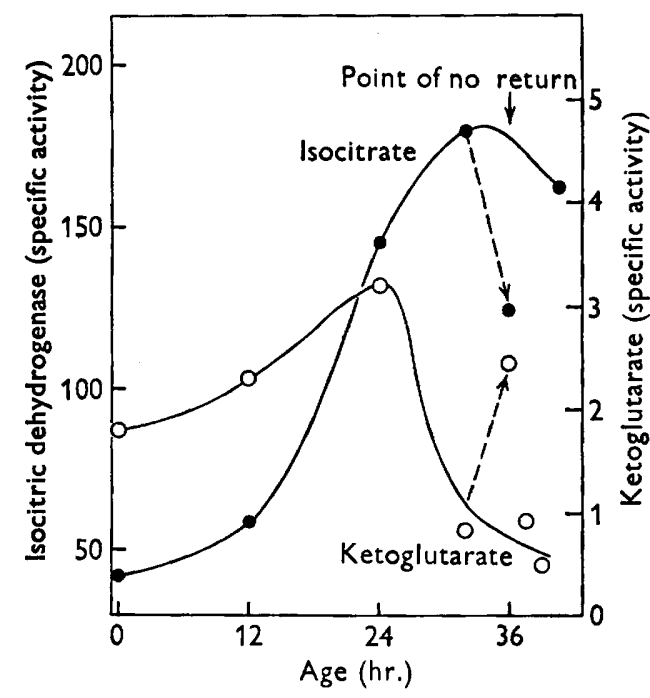

Fig. 2

Fig. 1. The total activities of isocitric dehydrogenase and $\alpha$-ketoglutaric dehydrogenase per RS plant at different stages of development. The total activities per plant at the spore stage $\left(\alpha\right.$-ketoglutaric dehydrogenase, $1.934 \times 10^{-7}$ unit; isocitric dehydrogenase, $4.52 \times 10^{-6}$ unit) were assigned values of $1 \cdot 0$, and all other total activities at different stages of development were related to the spore level (see Methods for details). The dotted lines represent the changes in activity induced by the removal of bicarbonate.

Fig. 2. The specific activities of isocitric dehydrogenase and $\alpha$-ketoglutaric dehydrogenase at different stages of development of an RS plant (see Methods for details). The dotted lines represent the changes induced by the removal of bicarbonate.

by washing, and then resuspended and agitated in water for $4 \mathrm{hr}$. at $24^{\circ}$. Under these conditions, such plants reverted to the alternative morphogenetic pathway and, by $36 \mathrm{hr}$., were ready to form papillae; i.e. they were fully mature thin-walled OC plants. Assays for enzymic activity in $32 \mathrm{hr}$. RS plants and the $36 \mathrm{hr}$. OC and RS plants derived therefrom (i.e. reversed and non-reversed, respectively) revealed that the morphological shift to an OC plant was associated with a pronounced and rapid enzymic shift; the specific activity of the $\alpha$-ketoglutaric dehydrogenase, 
which reached a low value at $32 \mathrm{hr}$., rose quickly once again; the specific activity of the isocitric dehydrogenase, which was in the process of ascending rapidly toward its peak, dropped sharply (Fig. 2). Even more pertinent from an interpretative point of view (see Discussion) were the per plant data, which revealed similarly striking reversals in total enzymic activity (Fig. 1). Under these identical conditions, however, the cytochrome oxidase and the glucose-6-phosphate dehydrogenase activities did not change significantly (Table 1). The significance of these observations is emphasized by analyses of RS plants subjected to the same treatment (i.e. removal of bicarbonate) after the point of no return in morphogenesis had been reached. At this later stage in ontogeny none of these enzymic activities changed appreciably following incubation for $4 \mathrm{hr}$. in the absence of bicarbonate.

\begin{tabular}{|c|c|c|}
\hline \multirow{3}{*}{$\begin{array}{l}32 \mathrm{hr} \text {. RS plants before incubation } \\
32 \mathrm{hr} \text {. RS plants after incubation }\end{array}$} & \multirow{3}{*}{$\begin{array}{c}\begin{array}{c}\text { Cytochrome } \\
\text { oxidase } \\
\text { Specifi }\end{array} \\
16 \cdot 9 \\
16 \cdot 5\end{array}$} & $\begin{array}{l}\text { Glucose-6- } \\
\text { phosphate } \\
\text { dehydrogenase } \\
\text { activity }\end{array}$ \\
\hline & & 8.9 \\
\hline & & $8 \cdot 1$ \\
\hline
\end{tabular}

See Methods for details.

\section{DISCUSSION}

The bicarbonate trigger mechanism for morphogenesis, as originally visualized from the results of experiments with multiple-generation cultures of Blastocladiella involves the gradual cessation of a weakly functional tricarboxylic acid cycle and, concomitantly, increased carboxylation of $\alpha$-ketoglutarate via a TPN-specific isocitric dehydrogenase as the developing plant becomes committed to the formation of a resistant sporangial (RS) plant (Cantino, 1961). More recently, data derived from experiments with synchronous, single-generation cultures have corroborated and amplified these notions (Cantino \& Lovett, 1960; Lovett \& Cantino, $1960 a, b$; McCurdy \& Cantino, 1960). In this report we have now provided more precise and direct evidence that the isocitric dehydrogenase activity required for carboxylation does indeed, increase quickly and many fold, while the enzyme system which would compete with it for $\alpha$-ketoglutarate by oxidatively decarboxylating this substrate ( $\alpha$-ketoglutaric dehydrogenase and an associated terminal cytochrome oxidase) decreases sharply. It is particularly noteworthy that during the development of an RS plant, bicarbonate also induces, simultaneously, an immediate exponential synthesis of isocitritase, a crucial enzyme required for removal of the isocitrate following its formation from $\alpha$-ketoglutarate via isocitric dehydrogenase. This does not occur in the absence of bicarbonate during the early stages of development in an ordinary colourless (OC) plant (McCurdy \& Cantino, 1960; Cantino, 1961).

An appreciable accumulation of evidence (Cantino \& Turian, 1959; Cantino, $1960,1961)$ suggests that these bicarbonate-induced changes in enzyme activity are intimately related in cause and effect fashion to the differentiation of an RS plant. On the basis of previous arguments (Cantino, 1961) and the data here reported, we are now strongly tempted to conclude that these alterations in measurable 
enzymic activity actually reflect bicarbonate-induced reversible changes in enzyme synthesis and enzyme degradation.

Before the point of no return in ontogeny, the bicarbonate-triggered morphogenetic mechanism leading to an RS plant remains plastic and reversible; the activities of two of the three key enzymes ( $\alpha$-ketoglutarate dehydrogenase, isocitric dehydrogenase) presumed to be most directly involved in this mechanism, seem to be equally plastic and reversible, responding quickly to the addition or removal of bicarbonate; the third, isocitritase, has not yet been tested for reversibility. Beyond the point of no return, when morphogenesis becomes irreversible and continues to completion, the same two enzyme systems lose their plasticity. These observations seem particularly significant in the light of the obvious lack of pliability in the activities of other enzyme systems, namely the TPN-specific glucose6-phosphate dehydrogenase and the terminal cytochrome oxidase, neither of which is directly involved in the bicarbonate trigger mechanism, nor is altered by the removal of bicarbonate, either before or after the irreversible point in morphogenesis.

The per plant data, however, provide the greatest support for our argument. While the morphogenetic shift is associated with a several-fold increase in the total $\alpha$-ketoglutaric dehydrogenase activity per plant and a sharp decrease in the total isocitric dehydrogenase activity per plant, neither the total cytochrome oxidase per plant, the total glucose-6-phosphate dehydrogenase activity per plant, nor the total protein per plant changes significantly. Thus the changes in enzyme activity cannot be artifacts resulting from an alteration of the total protein content of the fungus which would result in an apparent unidirectional change in specific activity. While it is always possible that some kind of ill-defined 'masking effect' has been induced by the removal of bicarbonate, this alternative explanation seems improbable.

There is little if any published evidence to show that induced enzymic synthesis is related in a cause-and-effect fashion to morphogenesis (Markert, 1958). In the light of these and earlier (Cantino, 1961) experiments, it seems very likely that, in Blastocladiella emersonii, bicarbonate does induce both synthesis and degradation of adaptive enzymes whose activities, in turn help to initiate and direct morphological differentiation.

This work was supported by research grants to the second author from the National Science Foundation, the National Institute of Health, and the Eli Lilly Company. Paper no. 60-23 from the Department of Botany and Plant Pathology, Michigan State University, East Lansing, Mich., U.S.A.

\section{REFERENCES}

Cantino, E. C. (1960). Relations of metabolism to cell development. In: Handbk. Pflanzenphysiologie, vol. 15, Heidelberg, Germany: Springer-Verlag.

Cantino, E. C. (1961). The relation between biochemical and morphological differentiation in non-filamentous aquatic fungi. Symp. Soc. gen. Microbiol. 11 (to be published).

Cantino, E. C. \& Horenstein, E. A. (1955). The role of ketoglutarate and polyphenol oxidase in the synthesis of melanin during morphogenesis in Blastocladiella emersonii. Physiol. Plant. 8, 189. 
Cantino, E. C. \& Horenstein, E. A. (1959). The stimulatory effect of light upon growth and carbon dioxide fixation in Blastocladiella III. Physiol. Plant. 12, 251.

Cantino, E. C. \& Hyatr, M. T. (1953). Further evidence for the role of the tricarboxylic acid cycle in morphogenesis in Blastocladiella emersonii. J. Bact. 66, 712.

Cantino, E. C. \& Lovetr, J. S. (1960). Respiration of Blastocladiella during bicarbonateinduced morphogenesis in synchronous culture. Physiol. Plant. 13, 450.

Cantino, E. C. \& Turian, G. F. (1959). Physiology and development of lower fungi (Phycomycetes). Annu. Rev. Microbiol. 13, 97.

Cavallini, D. \& Frontali, N. (1953). Determinazione cromatografica quantitativa dei chetoacidi. Recerca Scientifica, 23, 807.

Cavallini, D. \& Mondovi, B. (1957). The use of formaldehyde to avoid artifacts in the chromatographic determination of keto acids. Clin. chim. acta, $2,312$.

LovetT, J. S. \& CANTino, E. C. $(1960 a)$. The relation betwen biochemical and morphological differentiation in Blastocladiella emersonii. I. Enzymatic synthesis of glucosamine-6-phosphate. Amer. J. Bot. 47, 499.

LovetT, J. S. \& Cantino, E. C. (1960b). The relation between biochemical and morphological differentiation in Blastocladiella emersonii. II. Nitrogen metabolism in synchronous culture. Amer. J. Bot. 47, 550.

McCurdy, H. D. \& Cantino, E. C. (1960). Isocitritase, glycine-alanine transaminase, and development in Blastocladiella emersonii. Plant. Physiol. 35, 463.

Markert, C. L. (1958). Chemical concepts of cellular differentiation. In: A Symposium on the chemical basis of development. Ed. W. D. McElroy and B. Glass. Baltimore, Maryland, U.S.A.: Johns Hopkins University Press.

Stadtman, E. R., Novelit, G. D. \& Lipmann, F. (1951). Coenzyme-A function in and acetyl transfer by phosphotransacetylase system. J. biol. Chem. 191, 365. 